\title{
Performance Analysis of a Solar Thermal Generator with Dish Collector Equipped with Flat Mirrors for a Plant for the Reduction of Energy Consumption of University Residences
}

\author{
Mario Cucumo ${ }^{1}$, Vittorio Ferraro ${ }^{2}$, Dimitrios Kaliakatsos ${ }^{1 *}$, Francesco Nicoletti ${ }^{1}$, Davide Condò ${ }^{3}$ \\ ${ }^{1}$ Department of Mechanical, Energetics and Management Engineering (DIMEG), University of Calabria - Via P. Bucci - \\ 87036, Rende (CS), Italy \\ ${ }^{2}$ Department of Computer, Modelling, Electronics and System Engineering (DIMES), University of Calabria - Via P. Bucci - \\ 87036, Rende (CS), Italy \\ ${ }^{3}$ Freelance: C.da Nasari, 89900, Vibo Valentia, Italy
}

Corresponding Author Email: Vittorio.ferraro@unical.it

https://doi.org/10.18280/ti-ijes.642-437

Received: 12 April 2020

Accepted: 17 May 2020

Keywords:

performance analysis, solar thermal generator, dish collector, flat mirrors

\begin{abstract}
This article presents the development of the thermodynamic model and the analysis of the performance of a Solar Thermal Generator with parabolic collector for the evaluation and energy optimization of its fundamental parts. This type of Solar Thermal Generator is part of a solar concentration grid system for the generation of low enthalpy thermal energy used as an integration to the hot water production plant for some student residences of the University of Calabria (Italy). In this work is presented the algorithm of the optical model of concentrator of the Solar Thermal Generator through the Simulink ${ }^{\mathrm{TM}}$ software in order to determine in detail the thermal behaviour of the absorber. In addition, a thermo-fluid dynamic analysis was carried out in order to determine all the fundamental parameters that allow the global thermal balance of the Solar Thermal Generator to be carried out. Through a comparison with the first experimental data available, and, thanks to the use of a thermal imaging camera, a thermodynamic characterization of the absorber was carried out.
\end{abstract}

\section{INTRODUCTION}

At the University of Calabria (Italy) has been realized a field of solar concentrators which has as its objective the production of thermal energy for the integration of the existing hot water production plant for some student residences, and for the integration of air conditioning plant of the gym equipped with absorption heat pump (Figure 1).

In the literature there are various scientific works dealing with similar topics. The paper of Barlev et al. [1] focuses on innovation in CSP technologies over the last decade, while the paper of Zhang et al. [2] the different solar concentration systems are evaluated. Cucumo et al. [3, 4] have analysed the law of motion of reflectors for a concentrating solar Linear Fresnel plant by a method for optimally distributing the primary reflectors on the ground and afterwards a Linear Fresnel plant with primary reflectors movable around two axes.

In the paper of Sagade and Shinde [5] is highlighted the economic convenience of the use of solar concentrators for the production of hot sanitary water as well as in the paper Naika et al. [6], highlights the need to have government incentives to boost a technology that opens the way to production systems at medium enthalpy between $100^{\circ} \mathrm{C}$ and $250^{\circ} \mathrm{C}$, and finally the work developed at the Polytechnic of Turin (Italy) by Morciano et al. [7] shows that the annual efficiencies of twoaxis concentration systems are better with evacuated tube collector technologies and, above all, offer the possibility of annual use thanks to the high temperatures and the possibility of using solar cooling with absorption heat pumps.

The main purpose of the plant is to reduce the consumption of fossil fuel used (natural gas) and reduce environmental impact through the reduction of $\mathrm{CO}_{2}$ emissions into the atmosphere. As widely demonstrated in a case study located in Nigeria by Okoro and Madueme [8], the need to reduce the consumption of primary energy from fossil sources must be supported by investments in research and development and state incentives.

An efficient control system and an optimal and continuous maintenance, as widely documented in the work of the Ministry of New \& Renewable Energy (MNRE) of the Indian Government [9], is fundamental in the use of these technologies.

\section{MODELLING THE SOLAR CONCENTRATOR}

Particular attention was paid to the study of the absorber positioned inside the square receiver of the concentrator.

A data acquisition campaign is currently under way for longer periods of operation of the solar concentration field in order to be able to validate, in future papers, the models developed with greater accuracy.

The TGS H2.0 Solar Thermal Generator is equipped with a hardware and software device for pointing and moving on two axes to follow the apparent motion of the sun (Figure 1). 


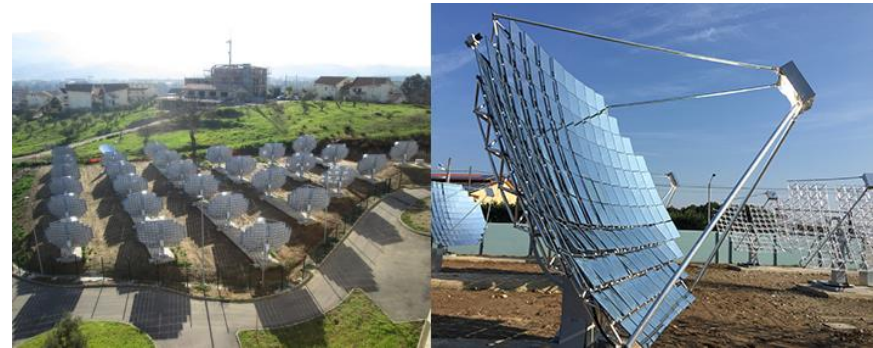

Figure 1. Solar concentration park and parabolic concentrator TGS H2.0 (Project S.r.1.)

The basic parameter of the collectors quantifying the achievable heat flow is the concentration ratio $\mathrm{C}$ :

$$
\mathrm{C}=\frac{\mathrm{A}}{\mathrm{A}_{\mathrm{r}}}
$$

The net absorbing area of the disk of TGS H2.0 is equal to $18 \mathrm{~m}^{2}$, and following the apparent movement of the sun, it reflects the sun rays on the $A_{r}$ area of concentrator equal to $0.15 \mathrm{~m}^{2}$ with a concentration ratio equal to 120 suns, and is able to develop, theoretically, temperatures up to $800^{\circ} \mathrm{C}$ and produce thermal energy equal to $167 \div 200 \mathrm{MJ} /$ day.

The structure of the capturing system is a paraboloid equipped with 130 flat square mirrors that reflect the parallel rays incident at a single point, called focus (Figure 2).

The distance between the fire and the vertex of the paraboloid, F, which depends on the curvature of the support structure of the mirrors, follows the law:

$$
\mathrm{F}=\frac{\mathrm{D}^{2}}{16 \cdot \mathrm{CP}_{\mathrm{P}}}
$$

For the paraboloid under test $C_{p}=0.55 \mathrm{~m}$ and $\mathrm{D}=4.79 \mathrm{~m}$.

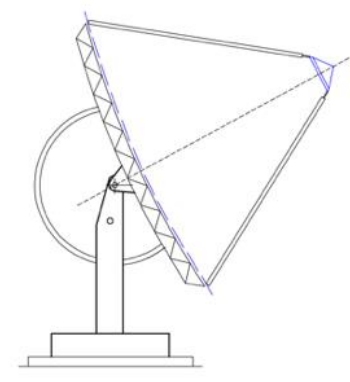

Dimensions in centimeters
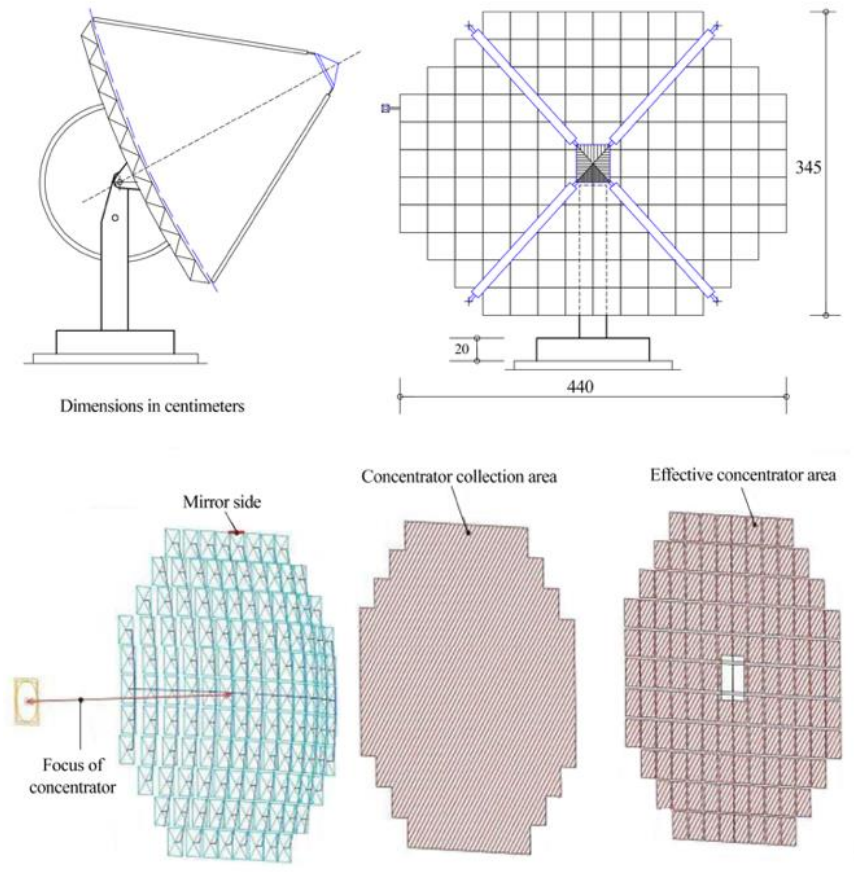

Figure 2. Geometric configuration of TGS H2.0
The receiver, placed on the focus of the concentrator, contains the absorber that absorbs the irradiation sent by the mirrors and transfer it to thermo-vector fluid to obtain outlet temperatures of about $70 \div 80^{\circ} \mathrm{C}$. The receiver of the system consists of a rectangular aluminium body and the receiver's collection area corresponds to the maximum diameter of the absorber that consists of a copper pipe wound so as to form a conical spiral (Figure 3).
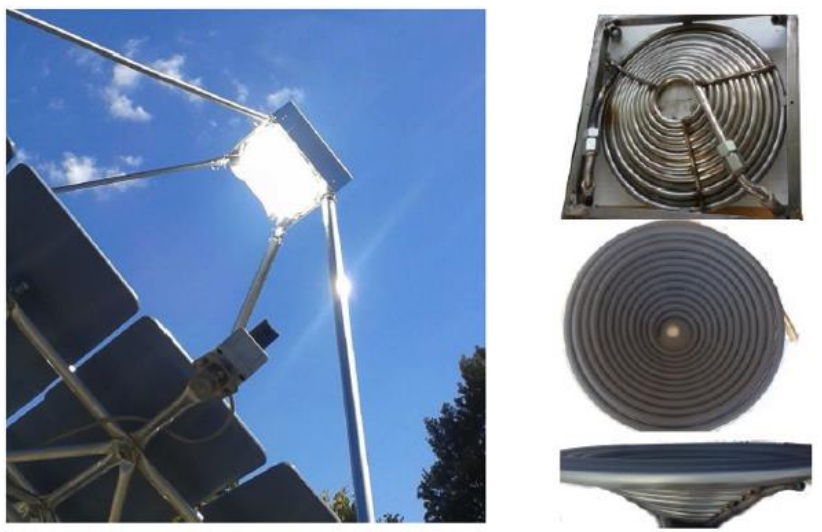

Figure 3. Receiver and absorber of TGS H2.0 (Project S.r.1.)

\section{ENERGY BALANCE OF THE CONCENTRATOR}

The interception factor, according to the theory of irradiation and calculation of form factor, Bergman et al. [10], determines the portion of irradiation coming from the concentrator that actually affects the square area of the receiver. The errors due to the starboard factor and the pointing error are difficult to evaluate and for simplicity in this paper the value of interception factor, $\mathrm{S}$, has been assumed as 1 .

The shading and spacing coefficient, E, takes into account the actual percentage of the area covered by mirrors, $A_{c}$, as gaps between the mirrors and the receiver shadow reduce the usable area and is provided by the manufacturer. In addition, the focus use factor, FU, that takes into account the fact that not all irradiation reflected by the mirrors hits the receiver, that suggested by the manufacturer equal to 0.9 has been used. As for the absorber surface absorption coefficient, $\alpha_{\mathrm{abs}}$, manufacturer suggests to take this equal to 0.8 , while the value of convective heat transfer coefficient of the air, $\mathrm{h}_{\mathrm{a}, \mathrm{c}}$, depends on the inclination and extension of the receiver opening. The Irradiation scatter correction factor, $\mathrm{F}$, that takes into account the fact that not all the power radiated by the absorber is actually lost, in this simulation was assumed equal to 1 , while the absorber's emission coefficient, $\varepsilon_{a b s}$, has been evaluated with thermography and is equal to 0.92 .

Once all parameters of the concentrator are known, it is possible to write the energy balance of the receiver evaluating its power and efficiency. Starting from the fundamental energy balance equation, valid for all concentration systems, and taking into account the terms related to heat exchange in the receiver, Madadi, et al. [11], and considering the interception factor, we obtain:

$$
\begin{aligned}
Q_{\text {out }} & =\left[\mathrm{I}_{\mathrm{b}, \mathrm{n}} \cdot \cos \theta_{\mathrm{i}} \cdot \mathrm{A}_{\mathrm{c}} \cdot \mathrm{E} \cdot \rho \cdot \mathrm{S} \cdot \mathrm{FU} \cdot \alpha_{\mathrm{abs}} \cdot \tau\right]- \\
& -\left[\mathrm{A}_{\mathrm{abs}} \cdot \mathrm{h}_{\mathrm{a}, \mathrm{c}} \cdot\left(\mathrm{T}_{\mathrm{abs}}-\mathrm{T}_{\mathrm{amb}}\right)\right]- \\
& -\left[\mathrm{A}_{\mathrm{abs}} \cdot \sigma \cdot \mathrm{F} \cdot \varepsilon_{\mathrm{abs}} \cdot \mathrm{h}_{\mathrm{a}, \mathrm{c}} \cdot\left(\mathrm{T}_{\mathrm{abs}}^{4}-\mathrm{T}_{\mathrm{amb}}^{4}\right)\right]
\end{aligned}
$$


The total efficiency of Solar Thermal Generator, evaluated for direct irradiation, is equal to the ratio between the thermal power yielded to the thermo-vector fluid and the solar power in its direct component intercepted by the reflective surface of the dish:

$$
\eta_{\text {tot }}=\frac{Q_{\text {out }}}{\mathrm{I}_{\mathrm{b}, \mathrm{n}} \cdot \mathrm{A}_{\mathrm{c}} \cdot \cos \theta_{\mathrm{i}}}=\frac{\dot{\mathrm{m}} \cdot \mathrm{c}_{\mathrm{pf}} \cdot \Delta \mathrm{T}_{\text {in }- \text { out }}}{\mathrm{I}_{\mathrm{b}, \mathrm{n}} \cdot \mathrm{A}_{\mathrm{c}}}
$$

The performance of concentrator is evaluated as the ratio between the incident power on the square receiver, $\mathrm{Q}_{\mathrm{rec}}$, and the incident power on the collector's area $\mathrm{A}_{\mathrm{c}}$ :

$$
\begin{aligned}
\eta_{\text {conc }} & =\frac{Q_{\text {rec }}}{I_{b, n} \cdot A_{c} \cdot \cos \theta_{i}}= \\
& =\frac{I_{b, n} \cdot A_{c} \cdot \cos \theta_{i} \cdot E \cdot \rho \cdot S \cdot \tau}{I_{b, n} \cdot A_{c} \cdot \cos \theta_{i}}=E \cdot \rho \cdot S \cdot \tau
\end{aligned}
$$

The efficiency of receiver is evaluated as the ratio between the useful power yielded to the thermo-vector fluid, ( $\left.\mathrm{Q}_{\text {out }}\right)$, and the solar power that actually affects the square receiver.

$$
\begin{aligned}
\eta_{\mathrm{rec}}= & \frac{\mathrm{I}_{\mathrm{b}, \mathrm{n}} \cdot \mathrm{A}_{\mathrm{c}} \cdot \cos \theta_{\mathrm{i}} \cdot \mathrm{E} \cdot \rho \cdot \mathrm{S} \cdot \tau \cdot \alpha \cdot \mathrm{FU}}{\mathrm{I}_{\mathrm{b}, \mathrm{n}} \cdot \mathrm{A}_{\mathrm{c}} \cdot \cos \theta_{\mathrm{i}}}- \\
& -\frac{\mathrm{A}_{\mathrm{abs}} \cdot \mathrm{h}_{\mathrm{a}, \mathrm{c}} \cdot\left(\mathrm{T}_{\mathrm{abs}}-\mathrm{T}_{\mathrm{amb}}\right)}{\mathrm{I}_{\mathrm{b}, \mathrm{n}} \cdot \mathrm{A}_{\mathrm{c}} \cdot \cos \theta_{\mathrm{i}}}- \\
& -\frac{\mathrm{A}_{\mathrm{abs}} \cdot \sigma \cdot \mathrm{F} \cdot \varepsilon_{\mathrm{abs}} \cdot \mathrm{h}_{\mathrm{a}, \mathrm{c}} \cdot\left(\mathrm{T}_{\mathrm{abs}}^{4}-\mathrm{T}_{\mathrm{amb}}^{4}\right)}{\mathrm{I}_{\mathrm{b}, \mathrm{n}} \cdot \mathrm{A}_{\mathrm{c}} \cdot \cos \theta_{\mathrm{i}}}
\end{aligned}
$$

\section{EVALUATION OF THE NET POWER OF ABSORBER WITH THE SIMULINK MODEL}

For the evaluation of the absorber power, the reflection of the ground and the irradiation emitted by nearby objects are considered negligible; the diffuse component of solar radiation has been neglected because the part of the diffuse radiation that reaches the absorber (directly or reflected by the mirrors) provides a negligible contribution, compared to that provided by direct irradiation.

Table 1 summarises the data used for the concentrator power balance using the Simulink model [12].

Table 1. Benchmarks for the power balance of the concentrator

\begin{tabular}{cccccc}
\hline $\begin{array}{c}\mathbf{I}_{\mathbf{b}, \mathbf{n}} \\
{\left[\mathbf{W} / \mathbf{m}^{2}\right]}\end{array}$ & $\begin{array}{c}\mathbf{A}_{\mathbf{c}} \\
{\left[\mathbf{m}^{2}\right]}\end{array}$ & $\begin{array}{c}\boldsymbol{\rho} \\
{[-]}\end{array}$ & $\begin{array}{c}\mathbf{S} \\
{[-]}\end{array}$ & $\begin{array}{c}\boldsymbol{\tau} \\
{[-]}\end{array}$ & $\begin{array}{c}\boldsymbol{\alpha}_{\text {abs }} \\
{[-]}\end{array}$ \\
\hline 850 & 12.5 & 0.74 & 1.0 & 1.0 & 0.8 \\
\hline
\end{tabular}

With these assumptions, starting from the intensity of the direct irradiation incident on the mirrors of reflecting surface of TGS H2.0, taking into account the various coefficients of reduction of the incident solar power referred to above, the useful power actually transferred to the absorber is determined.

Figure 4 shows the block diagram in Simulink environment, representative of the heat exchange of the entire system.

Table 2 shows the values for the different powers for this specific configuration obtained at the boundary of each component calculated with Simulink model.

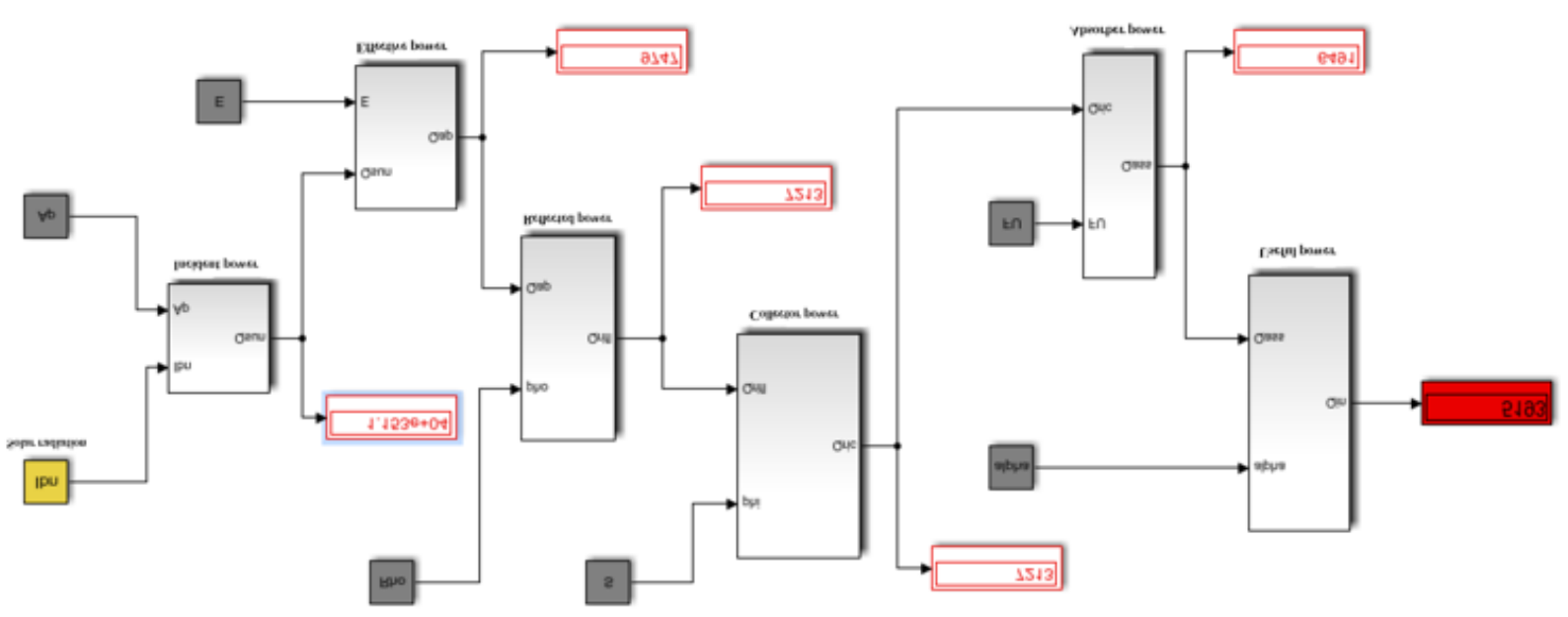

Figure 4. Block diagram in Simulink environment for the system power balance

Table 2. Power values of each component calculated with Simulink model

\begin{tabular}{cccccc}
\hline $\begin{array}{c}\mathbf{Q}_{\text {sun }} \\
{[W]}\end{array}$ & $\begin{array}{c}\mathbf{Q}_{\text {conc }} \\
{[W]}\end{array}$ & $\begin{array}{c}\mathbf{Q}_{\text {refl }} \\
{[W]}\end{array}$ & $\begin{array}{c}\text { Qrec } \\
{[W]}\end{array}$ & $\begin{array}{c}\mathbf{Q}_{\text {abs }} \\
{[W]}\end{array}$ & $\begin{array}{c}\mathbf{Q}_{\text {in,abs }} \\
{[W]}\end{array}$ \\
\hline 11534.5 & 9746.6 & 7212.5 & 7212.5 & 6491.2 & 5193.0 \\
\hline
\end{tabular}

\section{THERMO FLUID DYNAMIC ANALYSIS OF THE ABSORBER}

The absorber, positioned in the receiver, consists of a spiral wound pipe in order to improve the heat transfer coefficient, while the axial section of the pipe is approximately elliptical in order to obtain a better distribution of solar flow on the pipes, avoiding local temperature peaks. The spiral hose is flexible, in order to reduce the mechanical stresses of thermal expansion of the material. In addition, the pipe is coated with black paint to achieve a high coefficient of solar absorption.

The main heat exchange phenomena affecting the receiver are forced convection of the fluid inside the spiral, irradiance to the surrounding environment and natural convection inside the receiver based on numerical calculation models in the literature for solar dish concentrator, Sendhil Kumar et al. [13], 
Samanes et al. [14].

Figure 5 shows a simplified absorber scheme, while Table 3 shows the data used in the CAD model from measurements taken on the real absorber installed on the TGS H2.0.

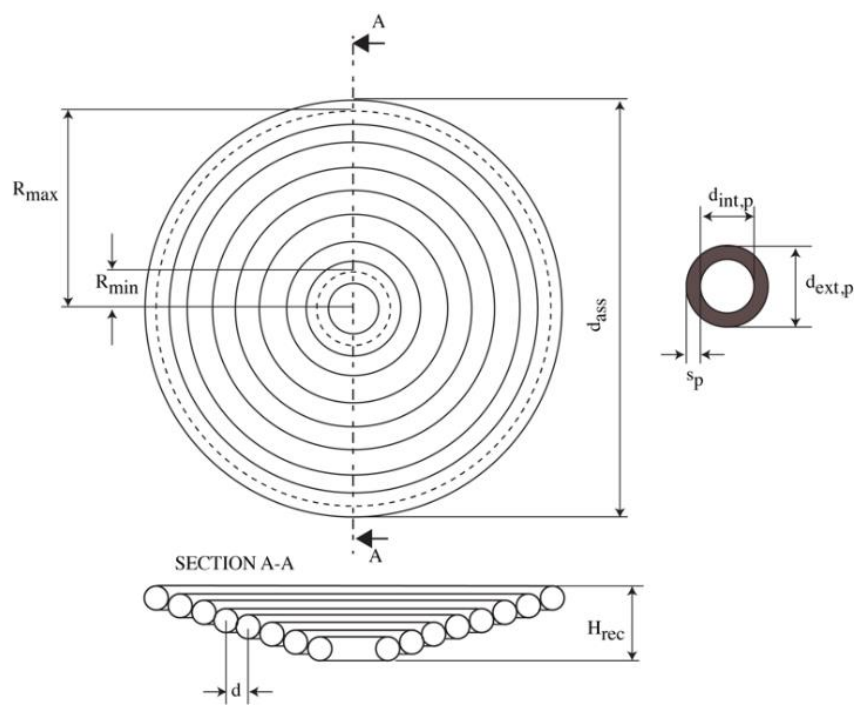

Figure 5. Simplified absorber scheme

Table 3. Absorber geometric data

\begin{tabular}{|c|c|c|c|}
\hline $\mathbf{d}_{\mathrm{abs}}[\mathrm{m}]$ & 0.42 & Ns [-] & 13.0 \\
\hline $\mathbf{d}_{\text {ext,p }}[\mathrm{m}]$ & 0.0165 & $\mathbf{L}_{\mathrm{sp}}[\mathbf{m}]$ & 9.507 \\
\hline $\mathbf{d}_{\text {int, }}[\mathbf{m}]$ & 0.0155 & $S_{\text {int, }}\left[\mathbf{m}^{2}\right]$ & $1.89 \times 10^{-4}$ \\
\hline $\mathbf{d}[\mathrm{m}]$ & 0.0156 & $A_{L-i n t}\left[m^{2}\right]$ & 0.463 \\
\hline $\mathbf{S p}_{\mathbf{p}}[\mathrm{m}]$ & 0.001 & $\mathbf{A}_{\mathrm{L}-\operatorname{ext}}\left[\mathrm{m}^{2}\right]$ & 0.523 \\
\hline $\mathbf{R}_{\max }[\mathbf{m}]$ & 0.21 & $\mathbf{H}_{\text {rec }}[\mathbf{m}]$ & 0.10 \\
\hline $\mathbf{R}_{\min }[\mathbf{m}]$ & 0.022 & & \\
\hline
\end{tabular}

The average reflection coefficient of the mirrors was experimentally measured with the FLIR E75 series infrared camera. This camera has a thermal sensitivity of less than $0.03^{\circ} \mathrm{C}$ at $30^{\circ} \mathrm{C}$ and an accuracy of $\pm 2{ }^{\circ} \mathrm{C}$. The determination of the emissivity of the mirrors was carried out using the method of direct measurement of the temperature by measuring the actual temperature of the material by means of a contact thermometer, the temperature of the receiver itself with the camera, aiming at the same point indicated by the contact sensor and varying the value of the emissivity imposed until you get the reading of the same temperature obtained with the contact sensor. The resulting emissivity is equal to $\varepsilon_{\mathrm{abs}}=0.92$. Figure 6 shows the thermographic image of the receiver.

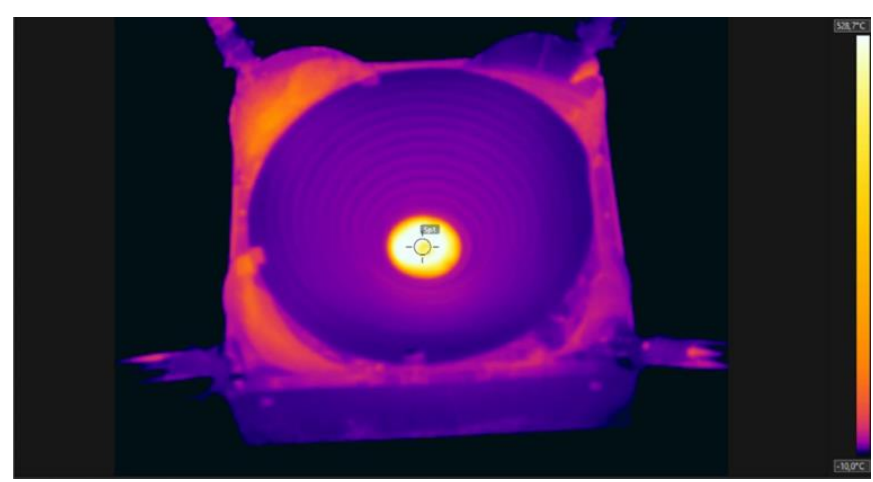

Figure 6. Thermographic image of the receiver
The CFD analysis was carried out exclusively for the absorber using the model just described and the results obtained are independent of the different meshes used. Figure 7 shows the various absorber views.

Since the absorber spirals are made of copper, it can be assumed that the temperature of the thermo-vector fluid of the entire absorber is considered uniform in each section. Moreover, it is plausible to consider the internal and external temperature of the pipe surface equal.

The back surface of the absorber is thermally insulated with a layer of rock wool and an outer sheet metal cover. Each spiral of the absorber emits energy by radiation, which is then absorbed by the other spirals. This contribution is only significant at temperatures above $200^{\circ} \mathrm{C}$. Furthermore, since the depth/opening ratio of the receiver is low, this additional contribution can also be neglected.

The boundary conditions consider a mass flow and temperature value and are set to the inlet section of the absorber. The outlet section is used to set the parameters for ambient pressure (static pressure) and temperature; the entire system is set to the surface flow value resulting from the calculation with the Simulink model.
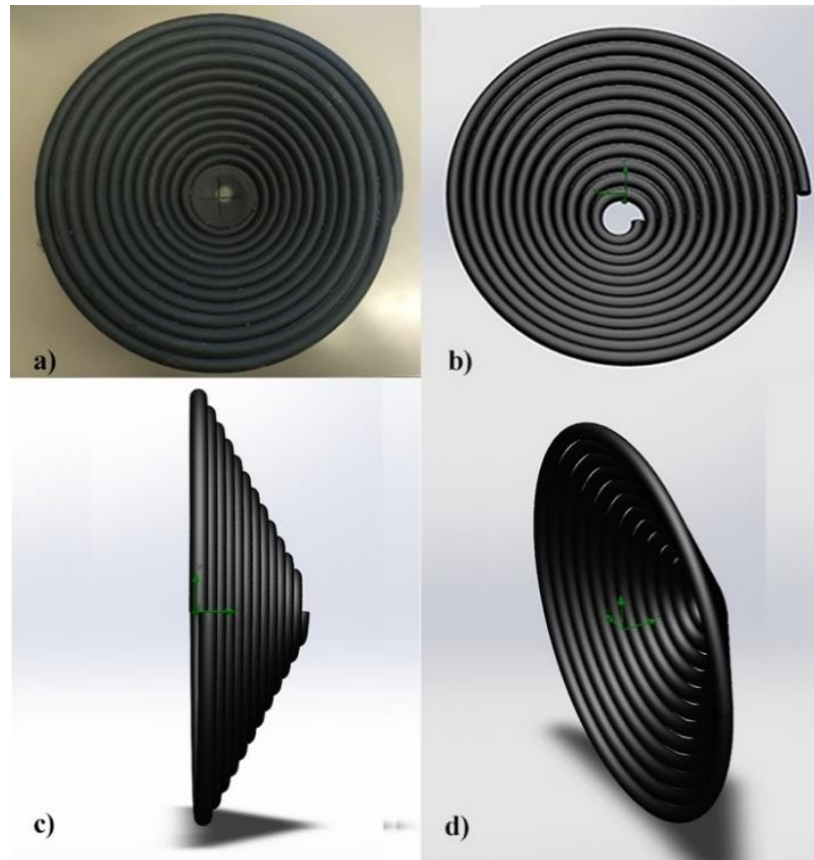

d)

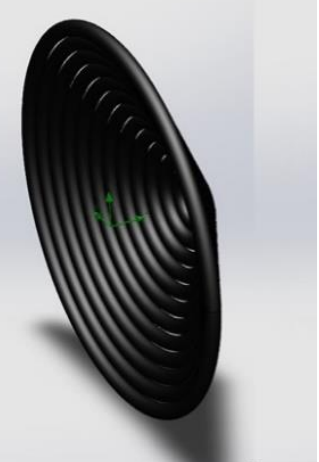

Figure 7. Absorber views: a) real component photo, b) CAD model, c) side view and d) isometric representation

The calculation was carried out in an iterative mode assuming an initial first attempt value for the mass flow. The procedure ends when a temperature difference of approximately $30^{\circ} \mathrm{C}$ of fluid is reached between the inlet and outlet sections of the spiral for thermo-vector fluid. Table 4 shows the values of the different quantities relative to the iteration considered valid, with $\Delta \mathrm{T}$ equal to $29.82 \mathrm{~K}$.

Table 4. Thermodynamic parameters obtained from the simulation with temperature difference approximately equal to $29.82^{\circ} \mathrm{C}$

\begin{tabular}{ccccc}
\hline $\begin{array}{c}\mathbf{T}_{\text {fin,1 }} \\
{[\mathbf{K}]}\end{array}$ & $\begin{array}{c}\mathbf{T}_{\text {fout,13 }} \\
{[\mathbf{K}]}\end{array}$ & $\begin{array}{c}\Delta \mathbf{T} \\
{[\mathbf{K}]}\end{array}$ & $\dot{\mathrm{m}}[\mathbf{K g} / \mathbf{s}]$ & $\begin{array}{c}\mathbf{Q}_{\text {out }} \\
{[\mathbf{W}]}\end{array}$ \\
\hline 313.74 & 343.56 & 29.82 & 0.04 & 4993.061 \\
\hline
\end{tabular}


Figure 8 shows, by way of example, the surface temperatures for windings obtained by fluid dynamic simulation.

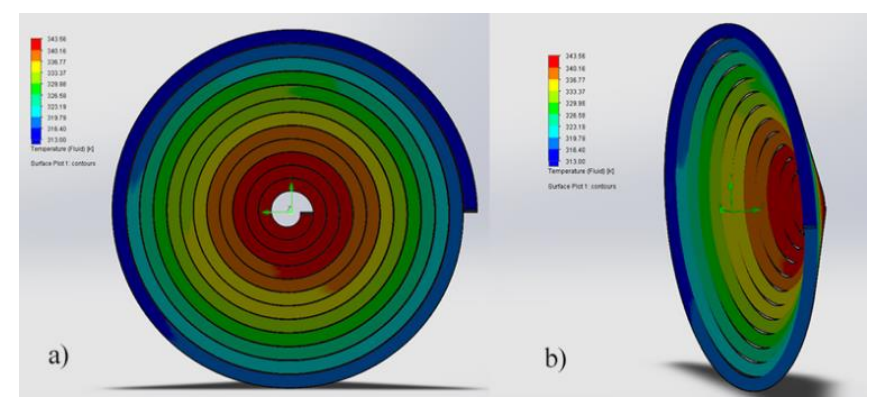

Figure 8. Surface temperatures for windings obtained with fluid dynamic simulation: a) frontal view and b) isometric view

Figure 9 shows the trend of temperature difference of thermo-vector fluid between the output and the input of each single spiral as the number of windings increases.

In Figure 10, on the other hand, is shown the trend of difference of thermal power exchanged for each single spiral as the number of windings increases.

As was to be expected, the first turns of the spiral are those in which there is the greatest exchange effect both at the level of temperature differences and at the level of power yielded to the thermo-vector fluid, which gradually decreases as the diameter of the winding decreases.

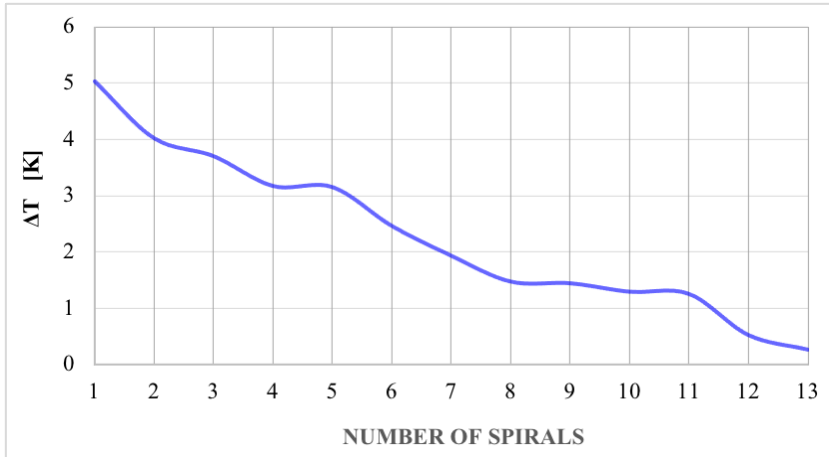

Figure 9. Trend of temperature difference of thermo-vector fluid between output and input of each spiral as the number of windings increases

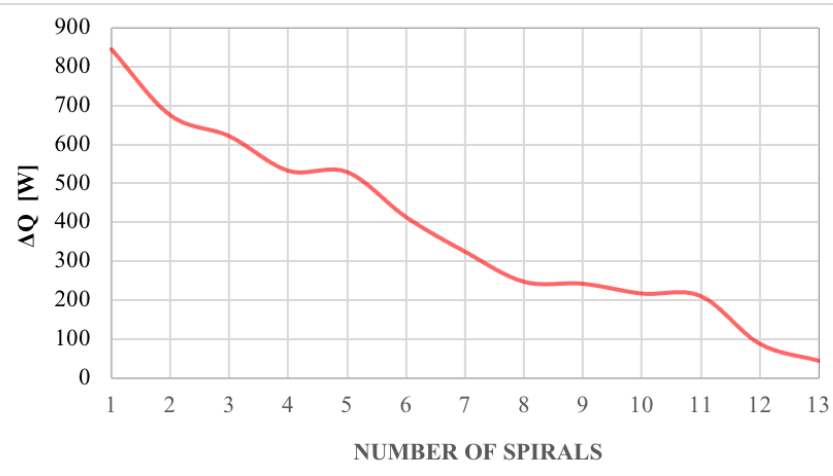

Figure 10. Trend of difference of thermal power exchanged for each single spiral as the number of windings increases

Figure 11 shows the percentages, with respect to the total power of absorber, of the various components of its energy balance resulting from the calculations.

It can be observed that the biggest absorber losses are those related to reflection $(22 \%)$, mirror spacing and receiver shadow $(16 \%)$.

From the thermo-fluid dynamics simulation, the different efficiencies have been obtained (Eq. (4)-(6)) and are shown in Table 5 .

It is noted that an increase in the reflectance coefficient would lead to a small increase in optical efficiency and therefore also in total efficiency.

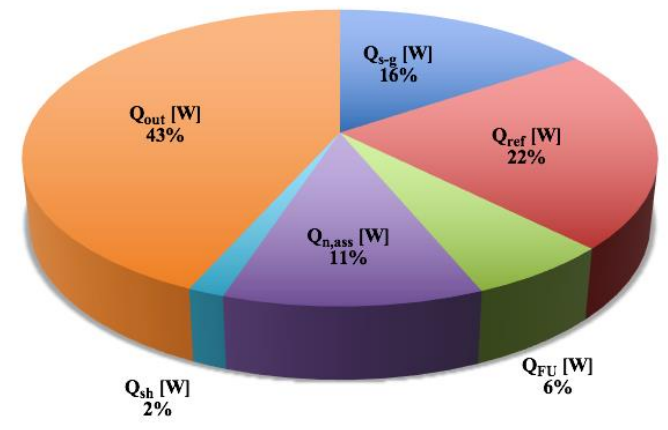

Figure 11. Absorber energy balance

Table 5. Efficiency of the various components of TSG $2.0 \mathrm{H}$

\begin{tabular}{ccc}
\hline $\boldsymbol{\eta}_{\text {tot }}$ & $\boldsymbol{\eta}_{\text {conc }}$ & $\boldsymbol{\eta}_{\text {rec }}$ \\
\hline 0.43 & 0.63 & 0.68 \\
\hline
\end{tabular}

\section{COMPARISON WITH EXPERIMENTAL DATA}

Before being marketed, the TGS H2.0 Solar Thermal Generator has been tested by a qualified and accredited laboratory at the request of the manufacturing company. From the data measured under test conditions, as prescribed by ISO 9806:2013 which, in addition to specifying the test methods for assessing the life, reliability and safety of fluid heating collectors, also includes test methods for the characterization of their thermal performance under stationary or almost dynamic conditions:

$$
\eta_{\mathrm{c}, \text { test }}=\eta_{0}-\mathrm{c}_{1} \cdot \frac{\mathrm{T}_{\mathrm{m}}-\mathrm{T}_{\mathrm{amb}}}{\mathrm{I}_{\mathrm{b}, \mathrm{n}}}-\mathrm{c}_{2} \cdot \frac{\left(\mathrm{T}_{\mathrm{m}}-\mathrm{T}_{\mathrm{amb}}\right)^{2}}{\mathrm{I}_{\mathrm{b}, \mathrm{n}}}
$$

where, $\eta_{0}=0.696, c_{1}=1.45\left(\mathrm{~W} / \mathrm{m}^{2} \mathrm{~K}\right)$ and $\mathrm{c}_{2}=0.025\left(\mathrm{~W} / \mathrm{m}^{2} \mathrm{~K}\right)$ the correlation constants referred to the gross area of the dish equal to $12.5 \mathrm{~m}^{2}$.

In order to experimentally define the performance curve of the concentrator, the experimental values of direct radiation, the temperature of the external environment air for the location and the values of the temperature of supply and return of thermo-vector fluid as well as the flow rate of the concentrator were used. The location of the plant is Arcavacata di Rende (CS), Italy (39 $19^{\prime}$ North, $16^{\circ} 11^{\prime}$ East).

A comparison was made between the performance of the system under test conditions and the performance obtained with the experimental data. For the calculation, a $\Delta \mathrm{T}$ of $30^{\circ} \mathrm{C}$ was used. An attempt has been made to maintain about $80^{\circ} \mathrm{C}$ of temperature of thermo-vector fluid at the outlet of the last winding by varying the flow rate of Table 6. 
Table 6. Experimental data for 22 June 2019

\begin{tabular}{cccccccc}
\hline Hour & $\mathbf{I}_{\mathbf{b}, \mathbf{n}}\left[\mathbf{W} / \mathbf{m}^{2}\right]$ & $\mathbf{T}_{\mathbf{a m b}}\left[{ }^{\circ} \mathbf{C}\right]$ & $\mathbf{T}_{\mathbf{m}}\left[{ }^{\circ} \mathbf{C}\right]$ & $\dot{\mathbf{m}}[\mathbf{K g} / \mathbf{s}]$ & $\mathbf{Q}_{\text {out,exp }}[\mathbf{W}]$ & $\begin{array}{c}\boldsymbol{\eta}_{\mathbf{c}, \text { test }} \\
{[-]}\end{array}$ & $\begin{array}{c}\boldsymbol{\eta}_{\mathbf{c}, \mathbf{e x p}} \\
{[-]}\end{array}$ \\
\hline 5 & 178.5 & 18.3 & 19.3 & 0.201 & 1259.97 & 0.688 & 0.565 \\
6 & 390.6 & 19.6 & 21.3 & 0.201 & 2855.93 & 0.689 & 0.585 \\
7 & 524.0 & 21.7 & 24.4 & 0.201 & 3947.90 & 0.688 & 0.603 \\
8 & 612.0 & 24.2 & 28.8 & 0.201 & 4703.88 & 0.684 & 0.615 \\
9 & 670.5 & 27.9 & 45.0 & 0.202 & 5335.46 & 0.648 & 0.637 \\
10 & 706.2 & 29.4 & 47.6 & 0.202 & 5650.40 & 0.647 & 0.640 \\
11 & 707.9 & 29.9 & 48.1 & 0.202 & 5665.73 & 0.647 & 0.640 \\
12 & 703.3 & 29.1 & 47.2 & 0.202 & 5631.09 & 0.647 & 0.641 \\
13 & 692.5 & 28.6 & 38.7 & 0.209 & 5633.50 & 0.671 & 0.651 \\
14 & 656.6 & 28.2 & 37.3 & 0.209 & 5327.81 & 0.673 & 0.649 \\
15 & 576.2 & 27.6 & 34.2 & 0.209 & 4716.42 & 0.677 & 0.655 \\
16 & 471.9 & 27.3 & 32.4 & 0.209 & 3825.54 & 0.679 & 0.649 \\
17 & 293.2 & 26.0 & 31.0 & 0.209 & 2358.21 & 0.670 & 0.643 \\
18 & 172.3 & 24.1 & 30.2 & 0.209 & 1310.12 & 0.639 & 0.608 \\
\hline
\end{tabular}

The experimental efficiency of the concentrator is defined by the following relationship:

$$
c, \exp =\frac{Q_{\text {out }, \exp }}{A_{c} X_{b, n}}
$$

Table 6 shows, by way of example, the experimental data for 22 June 2019.

Based on the experimental data, it was possible to calculate the useful power and efficiency of the concentrator. Figure 12 compares the test and experimental performance of the concentrator, while Figure 13 shows the trend of experimental useful power of the concentrator for 22 June 2019.

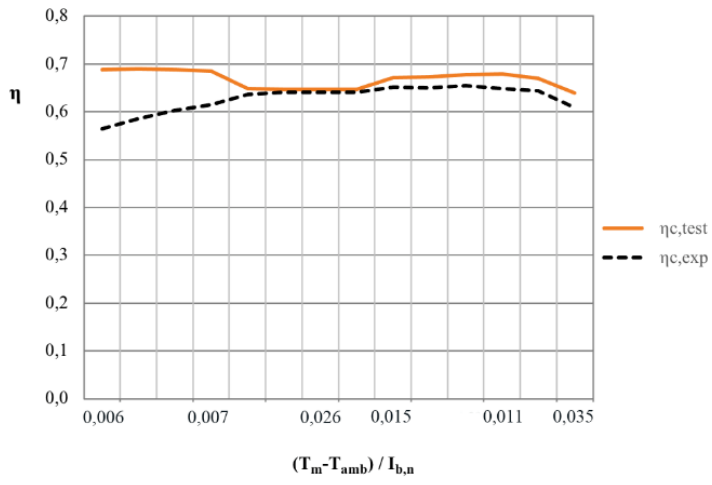

Figure 12. Comparison of test and experimental performance of the concentrator for 22 June 2019

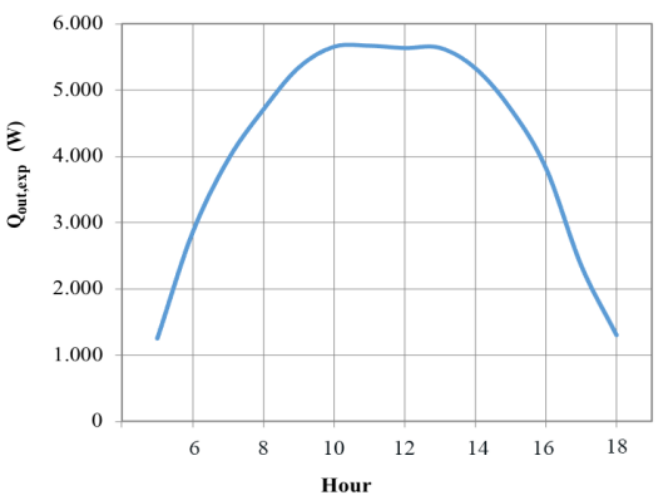

Figure 13. Trend of the experimental useful power of the concentrator for 22 June 2019

\section{CONCLUSIONS}

This paper presents the performance analysis of a Solar Thermal Generator with dish collector equipped with flat mirrors for a plant for the production of hot sanitary water, part of a park composed of 53 TGS $2.0 \mathrm{H}$ at the service of some student residences of the University of Calabria (Italy).

The modelling of the absorber has allowed the evaluation of the performance of TGS $2.0 \mathrm{H}$ starting from the test conditions and it has been possible to carry out the overall energy balance and an evaluation of the efficiency of heat exchange in the absorber thanks to the accuracy offered by the CFD code. The analysis made it possible to evaluate the loss factors and identified the construction elements that can be improved during the construction of TGS $2.0 \mathrm{H}$, such as the mirrors and their optimal distribution on the supporting structure as well as their reflectivity.

Finally, the experimental validation of TGS $2.0 \mathrm{H}$, in this first phase has allowed to evaluate the concentrator performance. The results of the latter analysis are consistent with the results of the accredited laboratory test.

In this first analysis of the system's performance, the first available experimental data were used. In a future work, since an experimental data collection campaign is in progress, a more detailed evaluation will be carried out of the performance of the Solar Thermal Generator, but also of the entire domestic hot water system fed by TGS H2.0.

\section{ACKNOWLEDGEMENT}

The authors thank Project S.r.l. for the support provided for the development of the paper.

\section{REFERENCES}

[1] Barlev, D., Vidu, R., Stroeve, P. (2011). Innovation in concentrated solar power. Solar Energy Materials \& Solar Cells, 95(10): 2703-2725. https://doi.org/10.1016/j.solmat.2011.05.020

[2] Zhang, H.L., Baeyens, J., Degréve, J., Cacéres G. (2013). Concentrated solar power plants: Review and design methodology. Renewable and Sustainable Energy Reviews, 22: 466-481. https://doi.org/10.1016/j.rser.2013.01.032 
[3] Cucumo, M., Ferraro, V., Kaliakatsos, D., Mele, M., https://doi.org/10.18280/ijht.35Sp0111

[4] Cucumo, M., Ferraro, V., Kaliakatsos, D., Nicoletti, F. https://doi.org/10.18280/ti-ijes.632-405

[5] Atul, S., Shinde, N. (2012). Performance evaluation of https://doi.org/10.1504/IJETP.2012.046015

[6] Naika, H., Baredar, P., Kumar, A. (2017). Medium Sustainable Energy Reviews, 76: 369-378. https://doi.org/10.1016/j.rser.2017.03.014

[7] Morciano, M., Fasano, M., Secreto, M., Jamolov, U., 956-963. https://doi.org/10.1016/j.egypro.2016.11.121

[8] Okoro, O.I., Madueme, T.C. (2004). Solar energy https://doi.org/10.1016/j.renene.2003.12.004

[9] Scheffler Dish based Solar System Operations \& India.

[10] Bergman, T.L., Incropera, F.P., DeWitt, D.P., Lavine, John Wiley \& Sons.

[11] Madadi, V., Tavakoli, T., Rahimi, A. (2014). First and https://doi.org/10.1515/jnet-2014-0023

[12] Mathworks, Simulink. https://it.mathworks.com/products/simulink.html, accessed on 12 August 2019.

[13] Sendhil Kumar, N., Reddy, K.S. (2067). Numerical https://doi.org/10.1016/j.solener.2006.11.008

[14] Samanes, J., García-Barberena, J., Zaversky, F. (2015). https://doi.org/10.1016/j.egypro.2015.03.063

\section{NOMENCLATURE}

A

$\mathrm{A}_{\mathrm{abs}}$

$\mathrm{A}_{\mathrm{c}}$

$A_{L-i n t}$

$\mathrm{A}_{\mathrm{L}-\mathrm{ext}}$ Nicoletti F. (2017). Law of motion of reflectors for a linear Fresnel plant. International Journal of Heat and Technology, 35(Sp.1): $\quad$ S78-S86. (2019). Solar tracking system for a linear Fresnel plant with two degrees of freedom reflectors. Italian Journal of Engineering Science, 63(2): 143-150. parabolic dish type solar collector for industrial heating application. International Journal of Energy Technology and Policy, 8(1). temperature application of concentrated solar thermal technology: Indian perspective. Renewable and Chiavazzo, E., Asinari, P. (2016). Installation of a concentrated solar power system for the thermal needs of buildings or industrial processes. Energy Procedia, 101: investments in a developing economy. Renewable Energy, 29(9): 1599-610. Maintenance Manual. UNDPGEF project on concentrated solar heat, Ministry of New \& Renewable Energy (MNRE). New Delhi (India). Government of A.S. (2011). Fundamentals of Heat and Mass Transfer. second thermodynamic law analyses applied to a solar dish collector. Journal of Non-Equilibrium Thermodynamics, 39(4): 183-19. investigation of natural convection heat loss in modified cavity receiver for fuzzy focal solar dish concentrator. Solar Energy, 81(7): 846-855. Modelling solar cavity receivers: A review and comparison of natural convection heat loss correlations. Energy Procedia, 69: 543-552.

$\mathrm{A}_{\mathrm{r}}$

C

$\mathrm{C}_{\mathrm{p}}$

$\mathrm{c}_{\mathrm{pf}}$

D

d

$\mathrm{d}_{\mathrm{abs}}$

$\mathrm{d}_{\text {ext,p }}$

$\mathrm{d}_{\text {int, } \mathrm{p}}$

$\mathrm{E}$

$\mathrm{F}$

FU

$\mathrm{h}_{\mathrm{a}, \mathrm{c}}$

$\mathrm{H}_{\mathrm{rec}}$

$\mathrm{I}_{\mathrm{b}, \mathrm{n}}$

$\mathrm{L}_{\mathrm{sp}}$

$\dot{\mathrm{m}}$

Ns

pop,max

$\mathrm{Q}_{\mathrm{abs}}$

$\mathrm{Q}_{\text {conc }}$

Q in,abs

$Q_{\text {sh }}$

$\mathrm{Q}_{\mathrm{FU}}$

$\mathrm{Q}_{\text {n,ass }}$

Q out

Qout,exp

$\mathrm{Q}_{\text {rec }}$

$\mathrm{Q}_{\text {ref }}$

Qrefl

$\mathrm{Q}_{\text {sun }}$

$\mathrm{Q}_{\mathrm{s}-\mathrm{g}}$

$\mathrm{R}_{\text {max }}$

$\mathrm{R}_{\min }$

$S$

$\mathrm{s}_{\mathrm{p}}$

$\mathrm{S}_{\text {int,p }}$

$T_{\text {amb }}$

$\mathrm{T}_{\mathrm{abs}}$

$\mathrm{T}_{\text {in }}$

$\mathrm{T}_{\text {fin, } 1}$

$\mathrm{T}_{\text {fout, } 13}$

$\mathrm{T}_{\mathrm{m}}$

net absorbing area of the disk $\left(\mathrm{m}^{2}\right)$

area of absorber $\left(\mathrm{m}^{2}\right)$

collectors area covered by mirrors $\left(\mathrm{m}^{2}\right)$

total internal lateral area of the coil $\left(\mathrm{m}^{2}\right)$

total external lateral area of the coil $\left(\mathrm{m}^{2}\right)$ area of receiver $\left(\mathrm{m}^{2}\right)$

concentration ratio of concentrator (-)

depth of the paraboloid (m)

specific heat at constant pressure of thermovector fluid $(\mathrm{J} / \mathrm{kg} \mathrm{K})$

diameter of the circumference of the net receiving surface of the paraboloid (m)

horizontal pitch of the coils (m)

diameter of absorber (m)

outer diameter of the pipe $(\mathrm{m})$

inner diameter of the pipe $(\mathrm{m})$

Shading and spacing coefficient (-)

irradiation scatter correction factor (-)

focus use factor (-)

convective heat transfer coefficient of the air $\left(\mathrm{W} / \mathrm{m}^{2} \mathrm{~K}\right)$

depth of receiver $(\mathrm{m})$

direct irradiation $\left(\mathrm{W} / \mathrm{m}^{2}\right)$

length of the mean line of the conical spiral (m)

Flow rate of thermo-vector fluid $(\mathrm{kg} / \mathrm{s})$

number of spirals (-)

maximum operating pressure (bar)

power incident on the absorber (W)

actual power collected by the concentrator (W)

power absorbed by the absorber (W)

absorber power lost due to shading (W)

absorber power lost due to low focus coverage (W)

absorber power lost due to non-absorption (W)

power yielded to the thermo-vector fluid (W)

experimental power yielded to the thermovector fluid (W)

power incident on the square receiver (W)

absorber power lost due to no ideal reflection (W)

Power reflected by the concentrator $(\mathrm{W})$

Solar power incident on the mirrors (W)

absorber power lost due to shading and spacing (W)

maximum mean radius of spiral (m)

minimum mean radius of spiral $(\mathrm{m})$

interception factor (-)

pipe thickness (m)

inner section of the pipe $\left(\mathrm{m}^{2}\right)$

outdoor air temperature $\left({ }^{\circ} \mathrm{C}\right)$

absorber operating temperature $\left({ }^{\circ} \mathrm{C}\right)$

inlet temperature of thermo-vector fluid to the receiver $\left({ }^{\circ} \mathrm{C}\right)$

temperature of thermo-vector fluid at the inlet of the first winding $(\mathrm{K})$

temperature of thermo-vector fluid at the outlet of the last winding $(\mathrm{K})$

mean temperature between the inlet temperature to the receiver and the outlet temperature of thermo-vector fluid from the receiver $\left({ }^{\circ} \mathrm{C}\right)$

$\mathrm{t}_{\mathrm{op}, \max } \quad$ maximum operating temperature $\left({ }^{\circ} \mathrm{C}\right)$

$\mathrm{T}_{\text {out }} \quad$ outlet temperature of thermo-vector fluid from the receiver $\left({ }^{\circ} \mathrm{C}\right)$ 


\section{Greek symbols}

$\alpha_{a b s}$

absorber surface absorption coefficient

$(-)$

$\Delta \mathrm{T}_{\text {in-out }}$

$\varepsilon_{\text {abs }}$

$\eta_{\text {conc }}$

$\eta_{c, \exp }$

difference between the input and output temperature of TGS $\left({ }^{\circ} \mathrm{C}\right)$

absorber's emissivity (-)

concentrator performance (-)

experimental concentrator performance

$(-)$ test concentrator performance (-)

receiver performance (-)

overall performance of TSG $2.0 \mathrm{H}(-)$

angle of irradiation incidence $\left(^{\circ}\right)$

mean coefficient of reflection of mirrors

$(-)$

Stefan-Boltzmann constant $\left(\mathrm{W} / \mathrm{m}^{2} \mathrm{~K}^{4}\right)$

coefficient of air transmission in the solar spectrum 